\title{
Probing the Charge Build-Up and Dissipation on Thin PMMA Film Surfaces at the Molecular Level by XPS**
}

\author{
Eda Yilmaz, Hikmet Sezen, and Sefik Suzer*
}

Electrets are well-known and utilized materials that develop a permanent electrostatic potential or a dipole moment. ${ }^{[1-6]}$ However, the nature of this "electrification" at the atomic and molecular scale is poorly understood. A better understanding of the fundamental processes that lead to electret formation could allow more intelligent utilization of these materials. Kelvin-probe atomic force microscopy (KP-AFM) has been the most advanced tool for probing, mapping, and quantifying the development of charge at submicrometer length scales. ${ }^{[7-16]}$ However, as in most electrical-based measurements, it lacks chemical specificity. In contrast, spectroscopic techniques such as IR, Raman, or NMR spectroscopy have excellent chemical specificity, but are not sensitive to charge accumulation. In this respect, ESR and EPR techniques have been quite successful in analysis of trapped charges. ${ }^{[17]}$ However, the use of these techniques is also limited to only radicals and paramagnetic species. Unlike optical techniques, $\mathrm{X}$-ray photoelectron spectroscopy (XPS) is a charged-particle-based technique and is also very sensitive to the presence of electrical potentials on the analyzed surfaces. Moreover, the photoelectron emission process itself leads to the creation of positive potentials in nonconductive samples as a result of uncompensated charges, and elaborate charge compensation methods have been developed using low-energy electrons or ions to eliminate sample charging. ${ }^{[18]}$ However, complete removal, that is, achieving the point of zero charge (PZC), is only an ideal. Besides, the measurement of the sign and the extent of the potentials developed can reveal significant information. ${ }^{[19-21]}$ Herein, we describe a contactless analysis technique to investigate the nature of the charging process of polymer surfaces at the molecular level, using XPS, whereby poly(methyl methacrylate) (PMMA) films are analyzed either in their pristine state or deliberately charged using a flood gun as an external electron source, and by applying external bias to control the extent of charging resulting from a combination of the photoemission process and the compensating electrons from the flood gun. ${ }^{[22-25]}$

[*] Dr. E. Yilmaz, Dr. H. Sezen, Prof. S. Suzer Department of Chemistry, Bilkent University Bilkent, TR-06800 Ankara (Turkey)

E-mail: suzer@fen.bilkent.edu.tr

[**; We are grateful to Dr. Ulrike Salzner and Dr. Margarita Kantcheva of Bilkent University for fruitful discussions, and to TUBITAK (The Scientific and Technological Research Council of Turkey) for financial support through the Grant No. 211T029. PMMA = poly(methyl methacrylate), XPS $=$ X-ray photoelectron spectroscopy. Supporting information for this article is available on the WWW under http://dx.doi.org/10.1002/anie.201201351.
Insulating materials such as polymers, salts, metal oxides, and nitrides have large band-gap values, and electrons are localized, leading to extremely low conductivities. In these materials, other electronic states, such as interface and impurity states, as well as defect sites, completely dominate their electrical properties. ${ }^{[17,26-29]}$ In addition, the electrical properties of these materials are influenced by external stresses, such as exposure to light, energetic particles, mechanical distortions, slicing, and ball milling, which is attributed to insertion of localized electrons or ions at interfaces, grain boundaries, cracks, or in bulk sites such as cavities. This charge insertion can even lead to chemical oxidation-reduction reactions. ${ }^{[30]}$ Contact electrification has recently been in focus. Two different mechanisms were proposed as its cause, one being electron transfer and the other ions or materials transfer, and sound experimental findings support both mechanisms. ${ }^{[7-11,31-33]}$

PMMA, with an average molecular weight of 120000 (Aldrich) was used to prepare films from $0.4 \%(\mathrm{w} / \mathrm{w})$ solution in chlorobenzene by spin coating onto conducting $\mathrm{Si}$ wafers. XPS measurements were carried out using a Thermo Fischer K-Alpha spectrometer, which was modified for the introduction of external bias to the substrate in the form of directcurrent (d.c.) or square-wave potential pulses with varying frequencies $\left(10^{-3}\right.$ to $\left.10^{6} \mathrm{~Hz}\right)$, as described previously. ${ }^{[25]}$ The instrument also provides a facility to record a narrow region of the spectrum in the snapshot mode with less than $50 \mathrm{~ms}$ steps. Different modes of data gathering are used to probe the sign, the extent, and the dynamics of charging/discharging in both the $\mathrm{C} 1 \mathrm{~s}$ and $\mathrm{O} 1 \mathrm{~s}$ regions. As prolonged exposure to $\mathrm{X}$ rays causes decomposition of the PMMA films, and because of the long-lasting nature of charging (several hundreds of seconds), extreme care was exercised to always probe a pristine region of the PMMA films for each and every measurement with an approximately $400 \mu \mathrm{m}$ X-ray spot size. Note also that, although the nature of charging is consistent, the measured potentials exhibit strong fluctuations from one film to the other and also across each film. Therefore, our results should be considered as qualitative findings for a proof of the principle.

Figure 1 displays the $\mathrm{O} 1 \mathrm{~s}$ and $\mathrm{C} 1 \mathrm{~s}$ regions of XP spectra that were recorded at three different charged states of a PMMA film, as judged by their positions referenced to the $\mathrm{Si} 2 \mathrm{p}_{3 / 2}$ peak of the substrate, and using the tabulated peak positions given in Table 1. ${ }^{[34]}$ Accordingly, if the recorded binding energy (BE) positions are less than the reference values, the kinetic energy of the photoelectron is increased with respect to neutral (PZC) state, and hence the sample is negatively charged (and vice versa). As can be gathered from the figure, in addition to the overall shift of peaks, measurable 


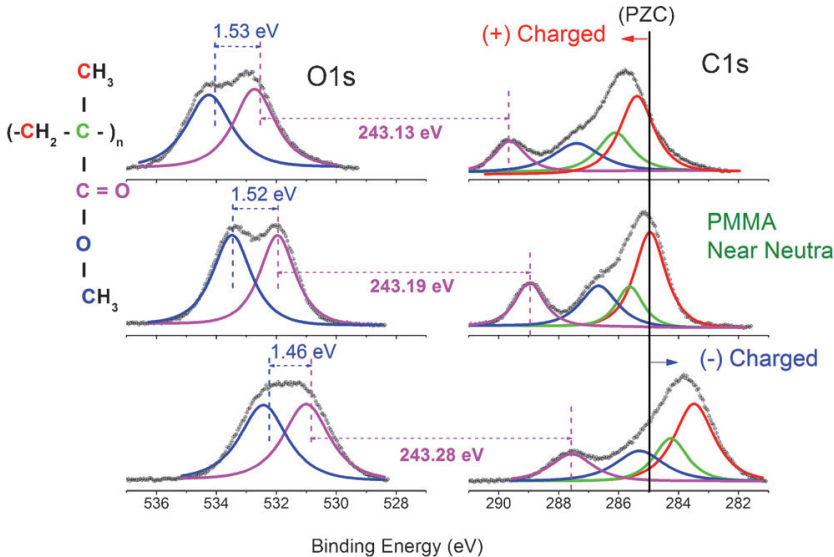

Figure 1. $O 1 \mathrm{~s}$ and $C 1 \mathrm{~s}$ regions of XPS spectra of a thin PMMA film, recorded under three different charging conditions. The point of zero charge (PZC) for the C1s peak of the backbone carbon atoms is shown for comparison.

Table 1: Reference binding energies and the energy differences (in eV) for $\mathrm{C} 1 \mathrm{~s}$ and $01 \mathrm{~s}$ peaks of PMMA. ${ }^{[34]}$

\begin{tabular}{ccccc}
\hline & $\begin{array}{c}\mathrm{CH}_{3} \text { or }-\mathrm{CH}_{2} \\
(285.00)\end{array}$ & $\begin{array}{c}-\mathrm{C}- \\
(285.72)\end{array}$ & $\begin{array}{c}-\mathrm{C}-\mathrm{O}- \\
(286.79)\end{array}$ & $\begin{array}{c}-\mathrm{C}=\mathrm{O} \\
(289.03)\end{array}$ \\
\hline$-\mathrm{C}=\mathrm{O}$ & & & & \\
$(532.21)$ & 247.21 & 246.49 & 245.42 & 243.18 \\
$-\mathrm{C}-\mathrm{O}-$ & & & & \\
$(533.77)$ & 248.70 & 248.05 & 246.98 & 244.74 \\
\hline
\end{tabular}

differential charging shifts are also observed in almost all atoms and groups. The most convincing shift is that between the $\mathrm{O} 1 \mathrm{~s}$ and the $\mathrm{C} 1 \mathrm{~s}$ peaks of the $-\mathrm{C}=\mathrm{O}$ groups, since the $\mathrm{C} 1 \mathrm{~s}$ peak is well separated from the other $\mathrm{C}$ peaks, and the $\mathrm{O} 1 \mathrm{~s}$ peak can be reliably curve-fitted. The analysis reveals that when the sample is positively charged the BE difference between the $\mathrm{O} 1 \mathrm{~s}$ and $\mathrm{C} 1 \mathrm{~s}$ of the carbonyl group $(243.13 \mathrm{eV})$, decreased by $0.06 \pm 0.02 \mathrm{eV}$ from the near neutral value of 243.19 , and increased by $0.09 \mathrm{eV}(243.28-243.19)$ when the sample becomes negatively charged. Methoxy groups also display similar shifts, most notably evidenced by the $0.07 \mathrm{eV}$ (1.53-1.46) decrease in the BE difference between the two oxygen atoms. All of these changes are reversible and reproducible.

Time-resolved measurements recorded in the snapshot mode are shown in Figure 2, which is an average of 10 different measurements at 10 different locations on the sample. Note that the spectra were recorded in 0.5-s time intervals to give a good $S / N$ ratio, as a result there is already a significant amount of charging shift even in the very first spectrum. However, findings parallel to those of the steadystate measurements are evident, as shown by the extracted data in Figure 3. Three of the most significant observations are as follows: as the system becomes more positively charged, 1) the measured $\mathrm{BE}$ difference between the $\mathrm{O} 1 \mathrm{~s}$ and the $\mathrm{C} 1$ s peaks of the carbonyl groups $(-\mathrm{C}=\mathrm{O})$ decreases (Figure 3a), 2) the difference between the two O1s peaks gradually increases (Figure $3 \mathrm{~b}$ ), and 3 ) the full width at half maximum (FWHM) of the carbonyl O1s peaks increases

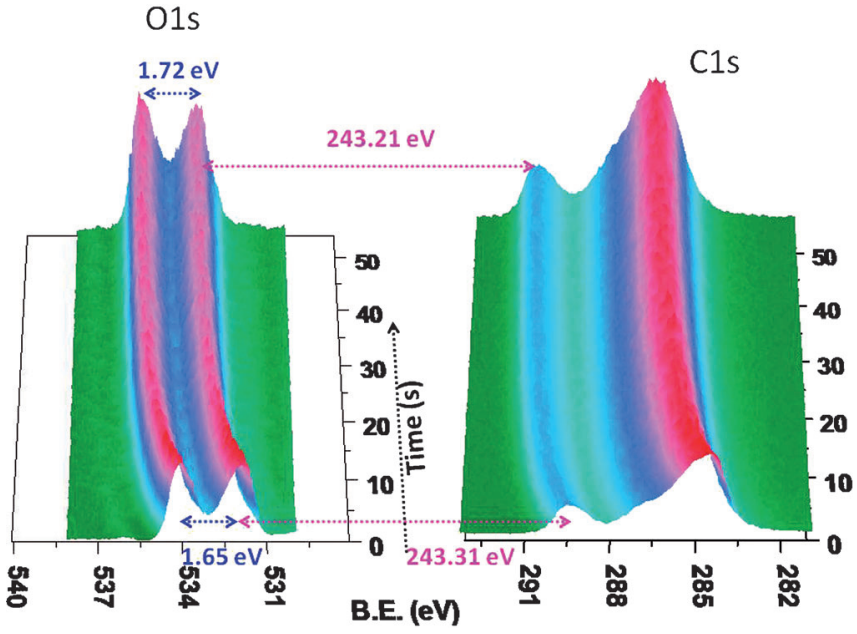

Figure 2. $\mathrm{O} 1 \mathrm{~s}$ and $\mathrm{C} 1 \mathrm{~s}$ XPS spectra of the PMMA film recorded in the snapshot mode as a function of time.
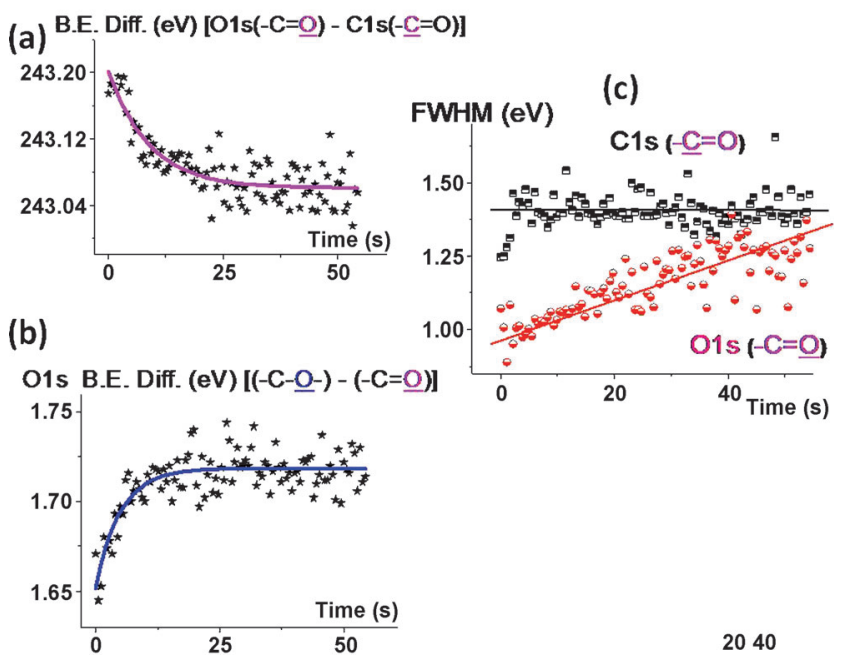

2040

Figure 3. Variation in the BE difference between: a) $\mathrm{O} 1 \mathrm{~s}$ and $\mathrm{C} 1 \mathrm{~s}$ peaks of the carbonyl groups, b) O 1s peak of the carbonyl and methoxy groups, and c) change of the FWHM value of the $C 1 \mathrm{~s}$ and 01 s peaks of the carbonyl groups.

(Figure 3c). All of these findings indicate that the carbonyl groups respond to the charging shifts more. In addition, the carbonyl oxygen atoms are more susceptible to the presence of charges. Similar observations were also reported two decades ago by Watts and co-workers for thin PMMA films cast on different oxide surfaces after peeling the film and analyzing the corresponding surface composition by XPS. ${ }^{[35-37]}$ They observed that the intensity ratio of the methoxy to carbonyl groups varied with respect to the acidbase property of the surfaces, and the carbonyl groups orient themselves towards the acidic (positively charged) surfaces such as $\mathrm{SiO}_{2}$, but shy away from basic (negatively charged) surfaces such as $\mathrm{MgO}$. In other publications, it was reported that the $\mathrm{C} 1 \mathrm{~s}$ peak of the methoxy groups of thin PMMA films on silicon exhibit a shift in binding energy of around $0.1 \mathrm{eV}$ at grazing angles, which was attributed to the higher concentration of the methoxy groups at the uppermost surface of the 
polymer film, and arising from the reduced relaxation during photoionization of the surface groups. ${ }^{[38-40]}$ Our findings are consistent with these earlier observations, but go far beyond them, since we report dynamic and completely reversible binding energy shifts with much improved information content at the molecular level.

To follow the state of the charging of the PMMA films, the Si substrate was subjected to an external electrical bias in the form of square waves with $5.0 \mathrm{~V}$ amplitude at $0.002 \mathrm{~Hz}$, both without and in the presence of low-energy electrons from the flood gun. The main purpose of such an exercise is related to the control of stray or flood gun electrons that suppress the charging effects when the sample is biased with $+5.0 \mathrm{~V}$. In contrast, under a bias of $-5.0 \mathrm{~V}$, all of these electrons are repelled away and the sample is left in its pristine form; hence any shift measured can be related to the presence (or absence) of charge on the sample before XPS analysis. The results are shown in Figure 4 for the binding energy of the composite $\mathrm{O} 1 \mathrm{~s}$ peak of the PMMA film as a function of time recorded again in the snapshot mode at 0.5 -s intervals. The net result can be summarized as follows: the PMMA film is initially negatively charged to $-2.0 \mathrm{~V}$. Under X-ray exposure, this potential is compensated by the holes created until a stable positive charge of around $1.0 \mathrm{~V}$ is developed and stays on the film in all subsequent cycles.

The fact that PMMA is observed to be in the negatively charged state at the beginning of the XPS measurements supports Bard's description of the presence of crypto electrons on these films. ${ }^{[27-30]}$

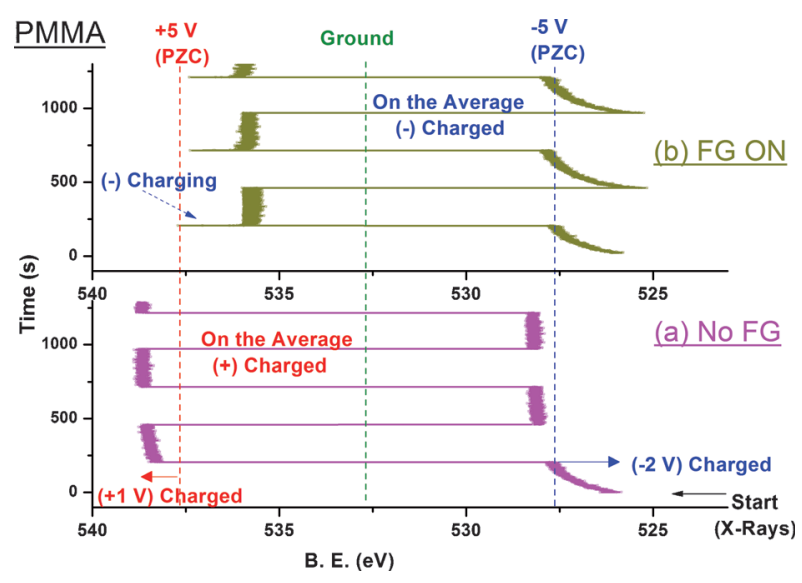

Figure 4. Variations in the $\mathrm{BE}$ value of the composite $\mathrm{O} 1 \mathrm{~s}$ peak under the influence of $5 \mathrm{~V}$ square-wave excitation: a) without, and b) in the presence of flood-gun electrons. The points of zero charge (PZC) under -5 and $+5 \mathrm{~V}$ cycles are also indicated for comparison.

When the flood gun is used the situation is different; again, the film starts negatively charged under $-5 \mathrm{~V}$ bias, but, upon flipping to $+5 \mathrm{~V}$, the low-energy electrons are attracted to the film and enable the film to return to its negatively charged state in less than $0.1 \mathrm{~s}$, which is reproduced in all subsequent cycles, and the film stays approximately $-2 \mathrm{~V}$ negatively charged overall, as schematically depicted both in Figures 4 and 5.

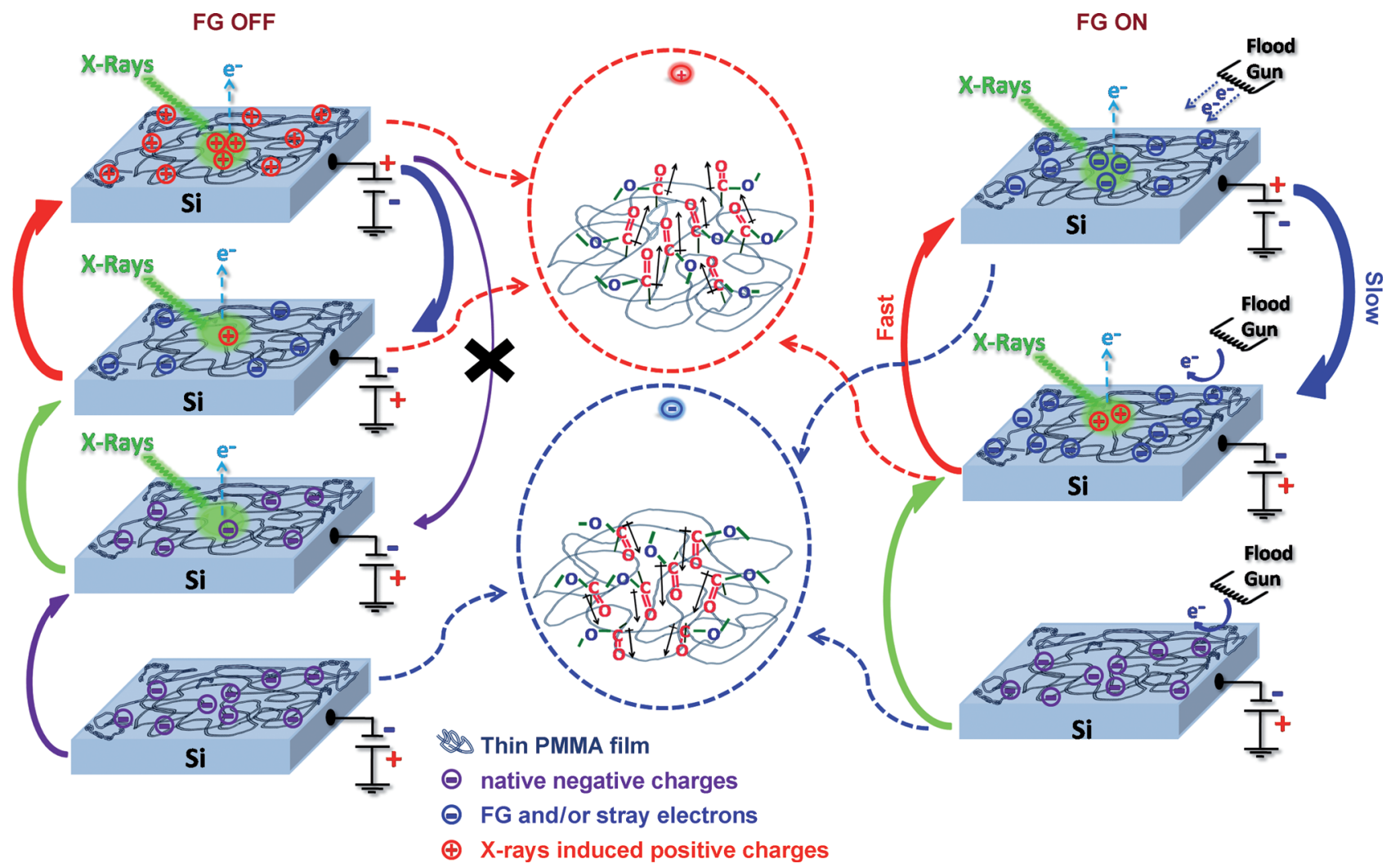

Figure 5. Schematics of the variations in the binding energy of the 01 s peak under the influence of square-wave excitation, with and without the flood gun. 
It was recently reported that by a combination of oxygen plasma treatment followed by stamping with polydimethylsiloxane, potentials as high as $+1.4 \mathrm{~V}$ were detected on PMMA surfaces, which corresponded to about $10 \mathrm{nCcm}^{-2}$ charge density on the surfaces. ${ }^{[12,13]}$ These findings are very similar to our measured voltages. Using the bulk density of $1.2 \mathrm{~g} \mathrm{~cm}^{-3}$ for the PMMA, ${ }^{[40]}$ we can estimate the monomer density to be around $4 \times 10^{14}$ units $\mathrm{cm}^{-2}$ on the surface, which reveals that approximately 1 out of $10^{4}$ monomer units carries a surface charge. What is really surprising is that the other 9999 monomer units feel the presence of such a charge and respond to it. Moreover, the pendant carbonyl groups respond more than the others, as schematically depicted in Figure 5. The observation that the binding energy of the $\mathrm{C}$ and $\mathrm{O}$ atoms of the carbonyl groups (and others) are influenced as much as $0.07 \mathrm{eV}$ is much more difficult to explain by a simple ion-dipole interaction argument, because, if we consider the carbonyl group having a dipole moment of around $1 \mathrm{D}$ interacting with a unit charge approximately $10 \mathrm{~nm}$ away (estimated from the monomer density mentioned above), the interaction energy would come to only $0.0001 \mathrm{eV}$ (see the Supporting Information), which is almost three orders of magnitude smaller.

An application of our methodology for the analysis of a PMMA/PS (polystyrene) junction is depicted in Figure 6. As schematically shown in the inset, the analysis was

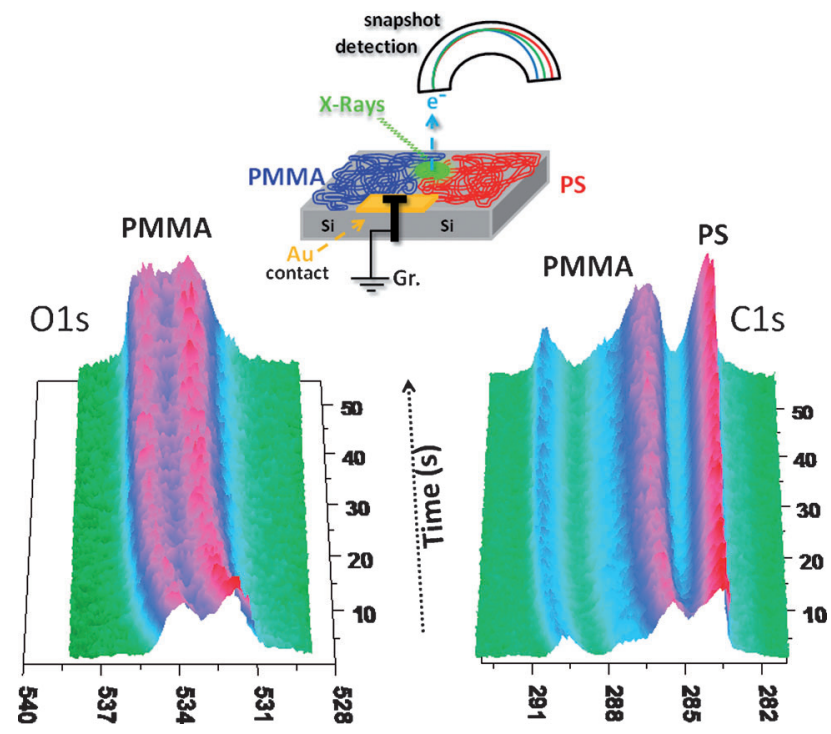

Figure 6. $\mathrm{O} 1 \mathrm{~s}$ and $\mathrm{C} 1 \mathrm{~s}$ regions of the PMMA/PS junction, recorded in the snapshot mode as the polymers are charging. The inset shows the details of the analyzed region of the two films put side by side.

purposely carried out around the contact line of the two separate thin films coated on silicon substrates and put side by side. Therefore, approximately $50 \%$ of the signal originates from PS and the rest from PMMA. At the beginning, the C1s peaks of PS and PMMA overlap, but, as positive charging develops, the location of the C1s peak of the PS stays more or less at the same energy but that of the PMMA starts to separate out, as a result of the large variations in the charging capacities of the two polymers. Nevertheless, the initial charging state of both polymers is negative.

In summary, charge-sensitive XPS measurement is a powerful tool for studying the electrical properties of polymeric and other dielectric material surfaces. We have demonstrated that this technique can be used to assess the charge-storage ability of polymer surfaces and its effects at the molecular level. In the experiments with PMMA films, we observed that the films are negatively charged at the beginning, but become positively charged during the course of the XPS measurements. In addition, we also have shown that carbonyl and methoxy groups have different tendencies to respond to negative and positive charges compared to the backbone atoms of the polymer. Moreover, there are measurable differences in the binding energies of carbon and oxygen atoms of the carbonyl groups when the surface is negatively and positively charged. The methodology is very powerful yet simple to implement. It is also quite general for analyses of various organic/inorganic composite surface structures. One future extension of our methodology is to improve the lateral resolution and also to incorporate enforced charging by contacting different materials (tribological series) or by the use of other stresses.

Received: February 17, 2012

Revised: March 19, 2012

Published online: April 18, 2012

Keywords: charge transfer - photoelectron spectroscopy · polymers - surface chemistry - time-resolved spectroscopy

[1] G. M. Sessler, Electrets (Topics in Applied Physics), Vol.33, Springer, Berlin, 1987.

[2] R. Schwödiauer, G. S. Neugschwandtner, S. Bauer-Gogonea, S. Bauer, T. Rosenmayer, Appl. Phys. Lett. 2000, 76, 2612-2614.

[3] a) H. Amjadi, J. Electrost. 2000, 48, 179-191; b) M. Paajanen, H. Valimaki, J. Lekkala, J. Electrost. 2000, 48, 193-204.

[4] R. Heydt, R. Pelrine, J. Joseph, J. Eckerle, R. Kornbluh, J. Acoust. Soc. Am. 2000, 107, 833-839.

[5] a) S. Y. Chou, L. Zhuang, J. Vac. Sci. Technol. B 1999, 17, $3197-$ 3202; b) E. Schaffer, T. Thurn-Albrecht, T. P. Russell, U. Steiner, Nature 2000, 403, 874-877.

[6] M. D. Morariu, N. E. Voicu, E. Schaffer, Z. Q. Lin, T. P. Russell, U. Steiner, Nat. Mater. 2003, 2, 48-52.

[7] A. F. Diaz, J. Adhes. 1998, 67, 111-122, and references therein.

[8] L. S. McCarty, A. Winkleman, G. M. Whitesides, J. Am. Chem. Soc. 2007, 129, 4075-4088.

[9] L. S. McCarty, G. M. Whitesides, Angew. Chem. 2008, 120, 2218 2239; Angew. Chem. Int. Ed. 2008, 47, 2188-2207.

[10] S. W. Thomas III, S. J. Vella, M. D. Dickey, G. K. Kaufman, G. M. Whitesides, J. Am. Chem. Soc. 2009, 131, 8746-8747.

[11] S. W. Thomas, S. L. Vella, G. K. Kaufman, G. M. Whitesides, Angew. Chem. 2008, 120, 6756-6758; Angew. Chem. Int. Ed. 2008, $47,6654-6656$.

[12] J. J. Cole, C. R. Barry, X. Y. Wang, H. O. Jacobs, ACS Nano 2010 , 4, $7492-7498$.

[13] X. Ma, D. Zhao, M. Xue, H. Wang, T. Cao, Angew. Chem. 2010, 122, 5669-5672; Angew. Chem. Int. Ed. 2010, 49, 5537-5540.

[14] J. J. Cole, C. R. Barry, R. J. Knuesel, X. Y. Wang, H. O. Jacobs, Langmuir 2011, 27, 7321-7329. 


\section{Angewandte}

[15] H. T. Baytekin, B. Baytekin, S. Soh, B. A. Grzybowski, Angew. Chem. 2011, 123, 6898-6902; Angew. Chem. Int. Ed. 2011, 50, $6766-6770$

[16] H. T. Baytekin, A. Z. Patashinski, M. Branicki, B. Baytekin, S. Soh, B. A. Grzybowski, Science 2011, 333, 308-312.

[17] M. Sakaguchi, Y. Miwa, S. Hara, Y. Sugino, K. Yamamoto, S. Shimada, J. Electrost. 2004, 62, 35-50.

[18] J. Cazaux, J. Electron Spectrosc. Relat. Phenom. 1999, 105, 155 185.

[19] H. Cohen, R. Maoz, J. Sagiv, Nano Lett. 2006, 6, 2462-2466.

[20] K. Shabtai, I. Rubinstein, S. R. Cohen, H. Cohen, J. Am. Chem. Soc. 2000, 122, 4959-4962.

[21] M. Dubey, I. Gouzman, S. L. Bernasek, J. Schwartz, Langmuir 2006, 22, 4649-4653.

[22] U. K. Demirok, G. Ertas, S. Suzer, J. Phys. Chem. B 2004, 108, 5179-5181.

[23] G. Ertas, U. K. Demirok, A. Atalar, S. Suzer, Appl. Phys. Lett. 2005, 86, 183110.

[24] H. Sezen, G. Ertas, A. Dana, S. Suzer, Macromolecules 2007, 40, 4109-4112.

[25] S. Suzer, H. Sezen, A. Dana, Anal. Chem. 2008, 80, 3931-3936.

[26] A. F. Diaz, R. M. Felix-Navarro, J. Electrost. 2004, 62, 277-290.
[27] M. Chiesa, M. C. Paganini, E. Giamello, D. M. Murphy, C. Di Valentin, G. Pacchioni, Acc. Chem. Res. 2006, 39, 861-867.

[28] V. Albrecht, A. Janke, E. Nemeth, S. Spange, G. Schubert, F. Simon, J. Electrost. 2009, 67, 7-11.

[29] S. Pelfrey, T. Cantu, M. R. Papantonakis, D. L. Simonson, R. A. McGill, J. Macossay, Polym. Chem. 2010, 1, 866-869.

[30] C. Y. Liu, A. J. Bard, Nat. Mater. 2008, 7, 505-509.

[31] C. Y. Liu, A. J. Bard, Chem. Phys. Lett. 2009, 480, 145-156.

[32] C. Y. Liu, A. J. Bard, J. Am. Chem. Soc. 2009, 131, 6397-6401.

[33] C. Y. Liu, A. J. Bard, Chem. Phys. Lett. 2010, 485, 231-234.

[34] G. Beamson, D. Briggs, High resolution XPS of organic polymers: the Scienta ESCA300 database, Vol. 4, Wiley, Chichester, 1992.

[35] M. M. Chehimi, J. F. Watts, S. N. Jenkins, J. E. Castle, J. Mater. Chem. 1992, 2, 209-215.

[36] M. M. Chehimi, J. F. Watts, J. Electron Spectrosc. Relat. Phenom. 1993, 63, 393-407.

[37] S. R. Leadley, J. F. Watts, J. Adhes. 1997, 60, 175-196.

[38] C. B. Duke, Surf. Sci. 1978, 70, 674-691.

[39] G. Beamson, D. Briggs, Mol. Phys. 1992, 76, 919-936.

[40] G. Beamson, D. Briggs, Surf. Interface Anal. 1998, 26, 343-351.

[41] R. C. Weast, M. J. Astle, W. H. Beyer, CRC Handbook of Chemistry and Physics, 55th ed., CRC, Boca Raton, FL, 1974. 